\title{
Appropriate algorithm method for Petrophysical properties to construct 3D modeling for Mishrif formation in Amara oil field
}

\author{
Jawad K. Radhy AlBahadily \\ Department of geology, college of science, Baghdad University, Baghdad, Iraq \\ Email: jawadkzm@gmail.com
}

\begin{abstract}
Geostatistical modeling technicality has utilized to build the geological models before scaling-up. Possible images of the area under investigation have provided from the methods that honor the well data and have the same variability computed from the original data. Property modeling is the process of filling the cells of the grid with discrete (facies) or continuous (petrophysics) properties. When interpolation between data points, propagate property values along the grid layers have executed. The main branch in the modeling algorithms obtainable is between Deterministic and Stochastic methods. In Petrel, both kinds of algorithms are available in the Facies and Petrophysical modeling processes. The process of well log up scaling is required to post values in each cell of the $3 D$ grid where each of the wells has situated; to achieve the averages well properties have used to populate each of the cells. This study has constructed based on thirteen wells penetrated Mishrif formation in Amara oil Field. This study has constructed based on thirteen wells (Am-1 to Am-13) penetrated Mishrif formation in Amara Oil Field. Three Dimension modeling has built depending to 12 wells (Am-1 to Am12) for Mishrif formation. All wells have PHIE and Water Saturation logs, which exported from the interactive Petrophysics software. Thereafter, scale up well logs has carried out for these wells. There are different methods of distribution of petrophysical properties. Eight methods have executed in order to propagate property values through construct Porosity and Water Saturation Models. Depending on results, the project has eight water saturation models and eight porosity models. Then insert new well (Am-13) to the modelsand create PHIE and Water Saturation logs from the Porosity and Water Saturation models where the new well penetrated the models in points, therefore, the new well have PHIE and water saturation logs for each method. With varying methods consequently, differences in results. Depending on comparing the results from Log interpretation and the results from models, there are no data from the modeling corresponding exactly to the true data from the log interpretation for the same well, but it approximate from the true data in different percentage. Sequential Gaussian Simulation suitable algorithm method to build the 3D modeling for Mishrif formation in Amara Oil Field.
\end{abstract}

Keywords - Deterministic algorithms, Mishrif Formation, Petrophysical properties, Reservoir modeling, stochastic algorithm.

\section{INTRODUCTION}

Geostatistical modeling technicality is widely used to build the geological models before scaling-up. Possible images of the area under investigation have provided from these methods that honor the well data and have the same variability computed from the original data. When few data are available or when data obtained from the wells are insufficient to have to characterize the petrophysical conduct and the heterogeneities of the field, further constraints are needed to gain a more factual geological model. For instance, seismic data or stratigraphic models can supply average reservoir information with an excellent area covering, but with a poor vertical resolution[1].

The procedure of preparing the input data into property modeling, it involves applying transformations on input data, identifying trends for continuous data, vertical proportion, and probability for discrete data. This is then utilized in the facies and petrophysical modeling to include that the same trends occur in the result.The Data Analysis utility lets analyze data interactively to gain a better understanding of the trends within your data. Also, benefit from an understanding of the relationships across all your data types[2].

\section{BASIC CONCEPTS}

Property modeling is the process of filling the cells of the grid with discrete (facies) or continuous (petrophysics) properties[3]. Petrel assumes that the layer geometry provided to the grid follows the geological layering in the model area. Thus, are these processes dependant on the geometry of the existing grid. When interpolation between data points, propagate property values along the grid layers will be executed by Petrel.The main branch in the modeling algorithms obtainable is between Deterministic and Stochastic methods in Petrel. Both kinds of algorithms are available in the Facies and Petrophysical modeling processes. 
With the same input, data will constantly grant the same outcome through Deterministic algorithms. These algorithms will generally run much quicker and are very transparent - it is easy to see why a particular cell has been given a particular value. The disadvantage is that models with little input data will automatically be smooth even though evidence and experience may suggest that this is not likely. Getting a good idea of the uncertainty of a model away from the input data points is often difficult in such models.

Stochastic algorithms use a random seed in addition to the input data, so while consecutive runs will give similar results with the same input data, the details of the result will be various. Sequential Gaussian Simulation included in Stochastic algorithms have more complex and therefore take much longer to run, but they do honor more aspects of the input data, the variability of the input data specifically. This means that local lows and highs will appear in the results which are not steered by the input data and whose location is simply an artifact of the random seed utilized. The result will have a distribution more typical of the real case, although the specific variation is unlikely to match. This can be useful, particularly when taking the model further to simulation as the variability of a property is likely to be just as important as its average value. The disadvantage is that some important aspects of the model can be random and it is important to perform a proper uncertainty analysis with several realizations of the same property model with diverse random seeds [2].

The aim of property modeling is to distribute properties between the wells such that it realistically preserves the reservoir heterogeneity and matches the well data [3].

\section{METHODOLOGY}

\subsection{Data Import}

Many data should be provided to Petrel software in order to construct a 3D model. Import data describes the data import procedure and the various data formats supported and organize the imported wells in sub folders. Well data were imported in three steps:

\subsubsection{Well Heads}

Well heads of twelve boreholes of Amara Oil Field, the well header information has been imported into Petrel, ( figure1). There are 15 default system attributes available in the attribute list [2]: The well name, UWI : the unique well identifier, Well symbol, Surface X coordinate, Surface Y coordinate, Kelly Bushing (KB) value, TD (TVD): the vertical depth value, TD (MD) : the measured depth value of the last point in the well, Top depth (MD) and Bottom depth (MD).

\subsubsection{Well tops}

Well tops of the reservoir units of Mishrif Formation have been also imported as well as the total depth of each well, which represents the markers for each unit, shows in figure (2).

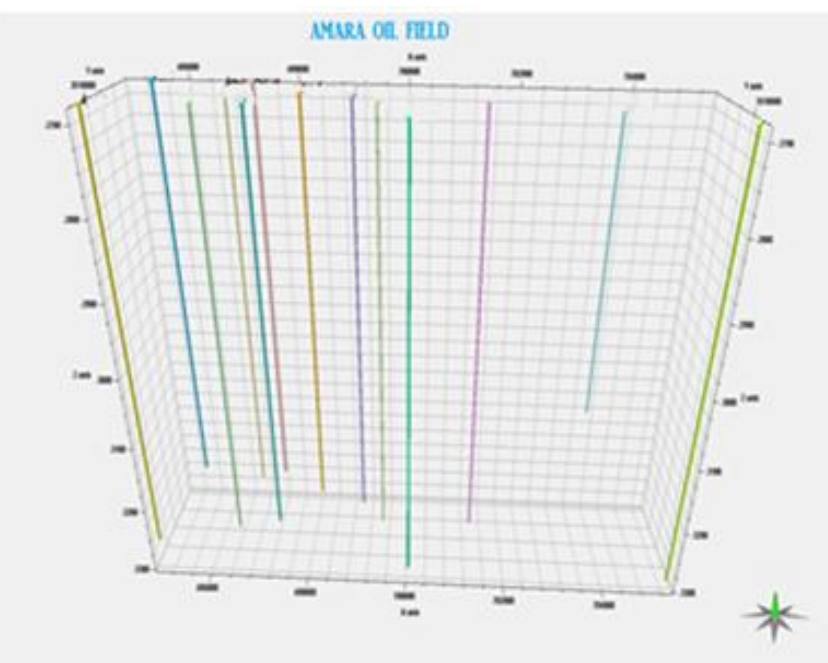

FIGURE 1: WELLS OF THE STUDY AREA

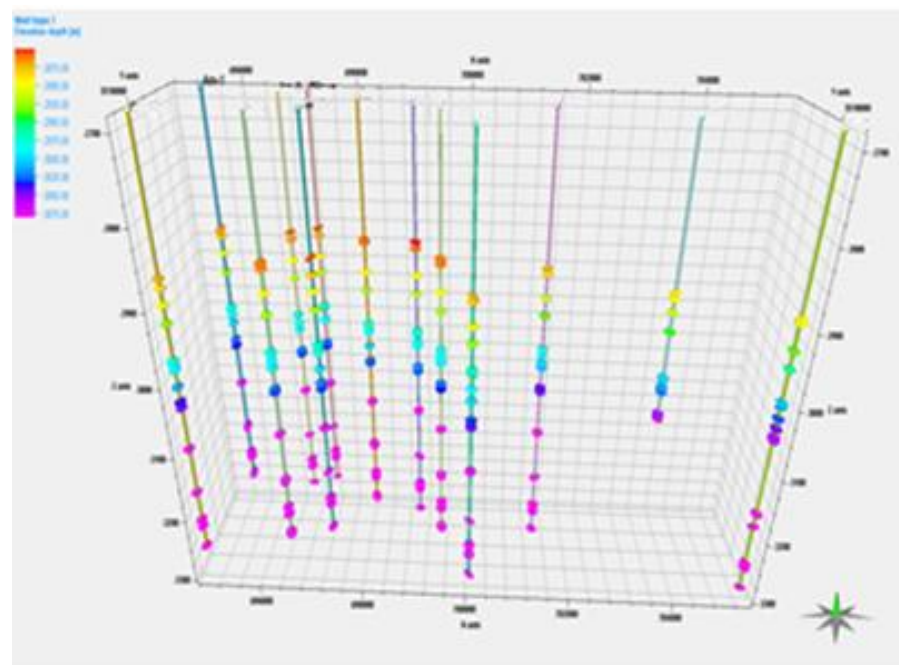

FIGURE 2: WELL TOPS OF THE STUDY AREA

\subsubsection{WellLogs}

This type of data included importing well logs (PHIE and SW logs) for each of the twelve studied wells that were exported from IP software of each well. Wells logs have shown in figure (3). 


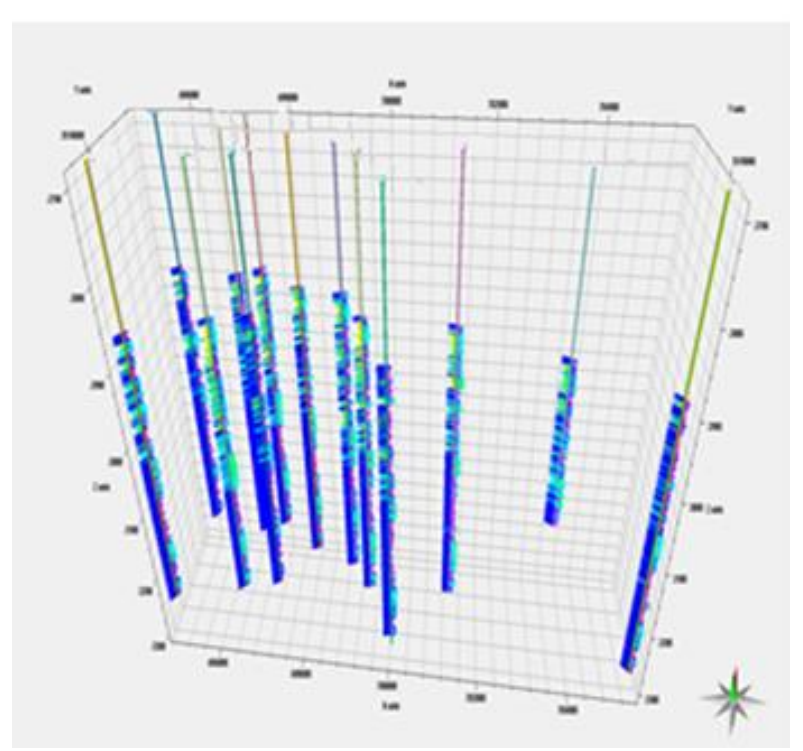

\section{FIGURE 3: WELLS LOGS OF THE STUDY AREA WITH PHIE AND SW}

\subsection{Structural Modeling}

A 3D structural model is made of geological interfaces such as horizons and faults honoring available observation data. These surfaces should fit the data within an acceptable range, depending on data precision and resolution[4].

A structure contour map is one of the most important tools for three-dimensional structural interpretation because it represents the full three-dimensional form of a map horizon. The mapping techniques to be discussed are equally applicable to surface and subsurface interpretation[5].

Structural maps were built depending on the well tops for all Amara wells as well as the available structural map for the top of Mishrif Formation from 2D seismic. Contour maps have been built to each zone of the formations figure (4) Structure Modeling of Mishrif Formation.

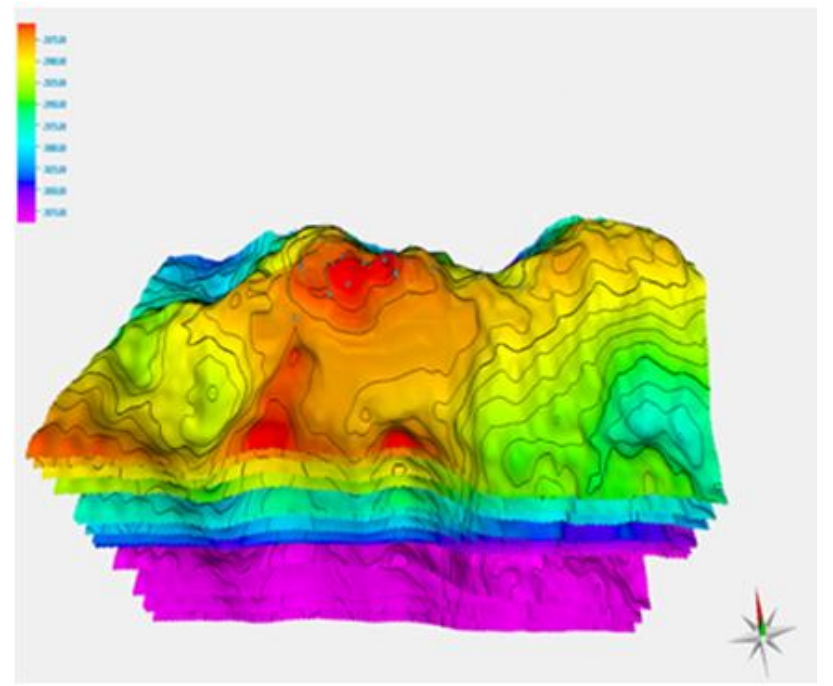

\section{FigURE 4: STRUCTURE MODELINF OF MISHRIF FORMATION}

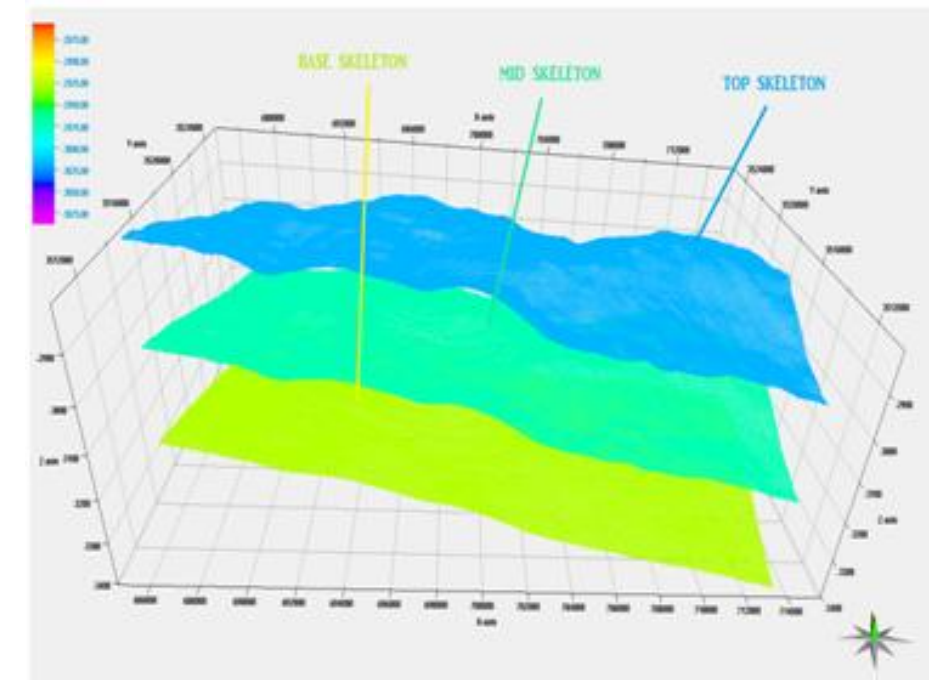

FIGURE 5: THE SKELETONS OF MISHRIF FORMATION IN AMARA OIL Field

\subsubsection{Pillar Gridding}

As a first step in building the framework of the 3D grid model, Pillar Gridding must be used in order to build the framework of the 3D grid. Pillar Gridding is the process of making the skeleton framework. The skeleton is a grid consisting of a Top, the Mid and Base skeleton grid as seen in the figure (5), each attached to the Top, the Mid and the Base points of the key pillars [6]. 


\subsubsection{Make horizons}

This process usually defines the main depositional units of the 3D grid. make horizon process inserts the inputs surfaces into the 3D grid.The inputs can be surfaces from seismic or well tops, line interpretations from seismic, or any other point or line data defining the surface.The make horizon process places all horizons defined directly from structure data into the 3D grid.The normally includes unconformity surfaces and primary horizons within sequences. The $3 \mathrm{D}$ grid these horizons are placed into consists only of pillars defined in the pillar Gridding process.The pillars define the corners of the cells that will ultimately be created in the 3D grid. Values are interpolated at each pillar based on nearby input data for the horizon. The interpolated values defined the surface in the 3D grid. The first step is to make horizons that honor the grid increment. The result after the Pillar Gridding process is a 3D grid consisting of a set of pillars connecting the Base, Mid, and Top Skeletons. The grid cell size is defined by the spacing between the pillars at a given vertical position[7]. Figure (6) represents horizons of the main units of Mishrif Formation.

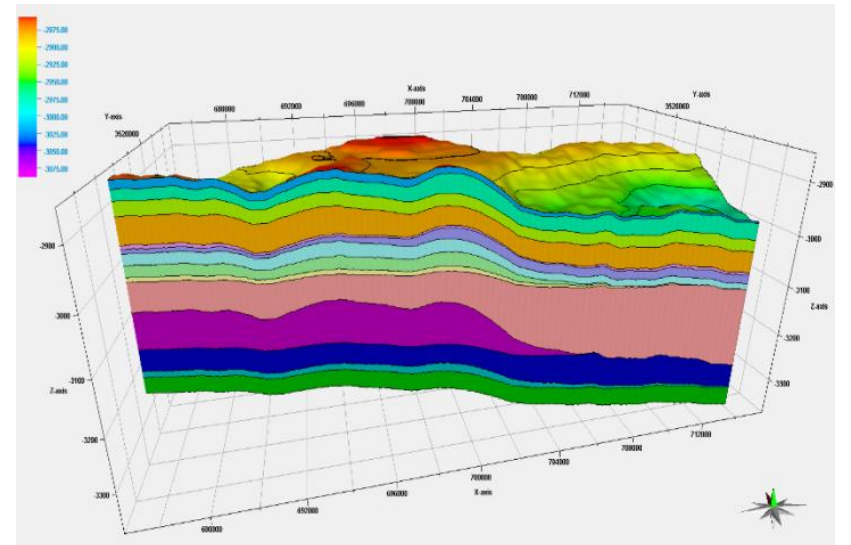

\section{FIGURE 6: SECTION SHOWS MAIN HORIZONS OF MISHRIF FORMATION}

\subsubsection{Layering}

The final step in building the structural framework is to define the thickness and orientation of the layers between horizons of the 3D Grid. These layers, in conjunction with the pillars, define the cells of the 3D Grid that are assigned attributes during property modeling. The Layering process will only make a finer resolution of the grid and no input data is used for this process. The vertical resolution of the grid can define by setting the cell thickness, defining a number of cells or using a fraction code. When specifying the cell thickness, the zone division can either follow the base or the top of the zone.

The layers should be defined based on the properties to be modeled. Usually, the layer thickness should be the thickness of the thinnest facies to be modeled. However, the number of cells increases when the layer thickness decreases, [6]. Each reservoir unit in Mishrif formation has been divided into many layers depending on facies and petrophysical properties as illustrated in figure (7). MA is divided into 5 layers, MB11 has been divided into 6 layers, MB12 unit has been divided into 3 layers, MB21 unit has been divided into 5 layers, MC1 unit has been divided into 3 layers, and MC2 unit has been divided into 3 layers.

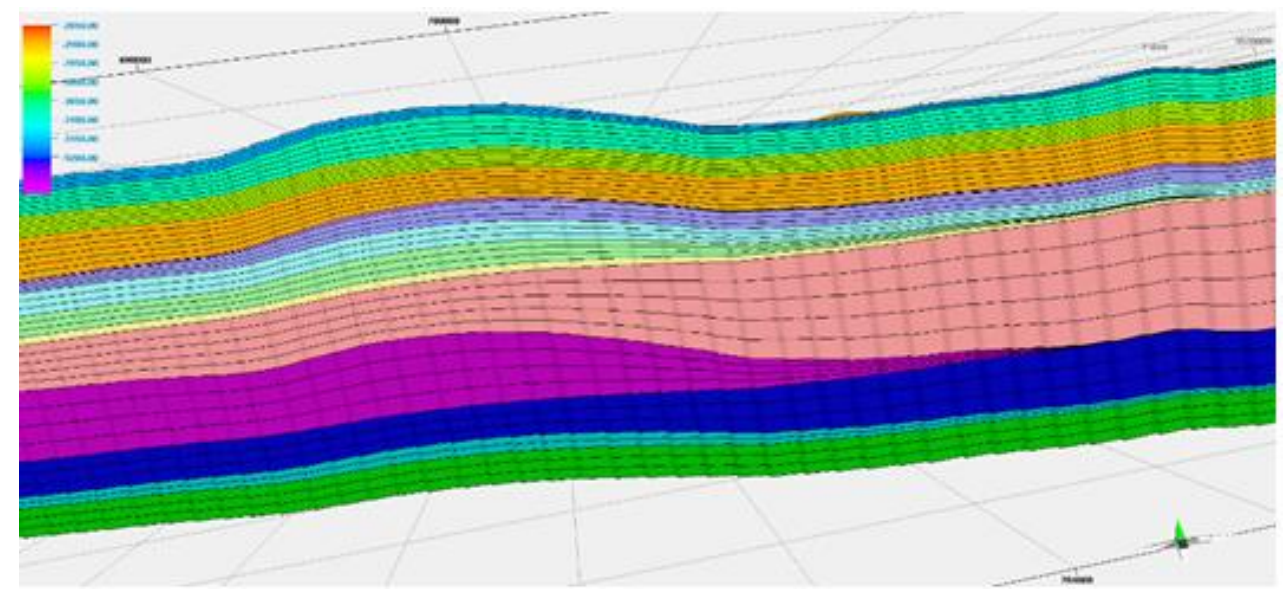

FIGURE 7: THE LAYERING IN THE MISHRIF FORMATION 


\subsection{Scale up Well logs}

The process of well log up scaling is required to post values in each cell of the 3D grid where each of the wells is situated; to achieve these average well properties are used to populate each of the cells. To choose the setting parameters for the upscaling in terms of the averaging method, log treatment as lines or points and method of upscaling are applied. In terms of the setting properties the logs are treated as lines or points; the setting using points means that the logs are treated as points and only the point values would be used in making this averages. Line averages mean that the logs are treated as lines such that line values outside upscaled cells can also be used interpolated averages in between log points. The upscaling methods are dived into simple, through cell and Neighbour cells.

The upscale well logs with different averaging methods require the process of data analysis as a basis to control the property of the models.

The simple method is used to give property values to cells as much as the wells penetrate the cells, no matter how tiny the cells are in dimension. The Through cell method gives a value to a cell only when opposite cell walls are penetrated by the cells; this is to ensure that only a tiny section of the well path does not provide only the reasonable confidence to post values to the cell as in the case of the simple method. The last method is the Neighbor cells which is similar to the simple method where all cells are posted with values as far as the well penetrate them, the variant is that cells adjacent one another in the same layer would be averaged. (Ahanor, 2012). The simple method has used in carrying out the upscaling process as applied in the Amara Oil Field field shows in figures (8) and (9).
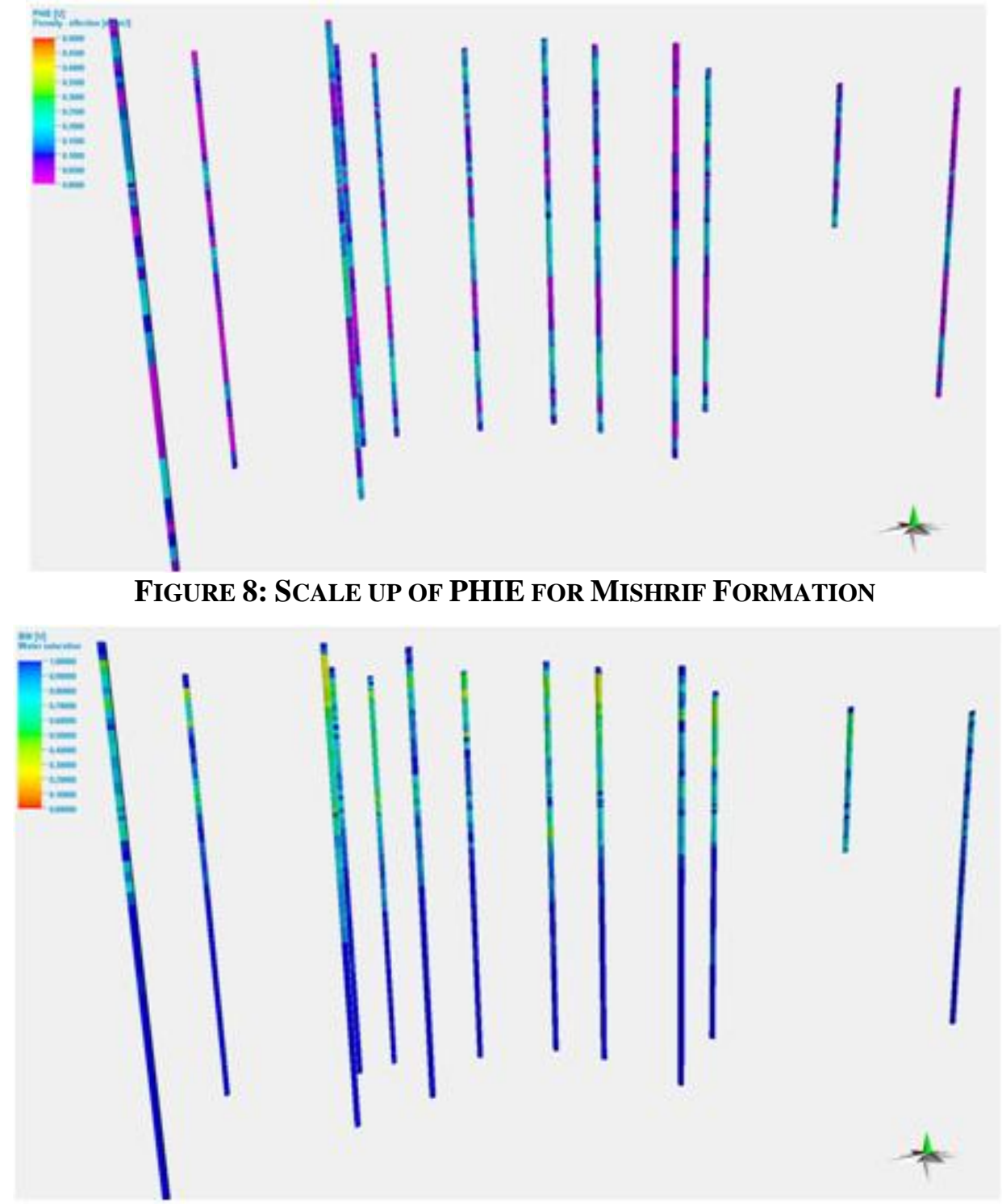

FigURE 9: SCALE UP OF WATER SATURATION FOR MISHRIF FORMATION 


\subsection{Petrophysical Model}

The aim of a geological reservoir model is to provide a complete set of continuous reservoir parameters (i.e. porosity and water saturation) for each cell of the 3D grid. Many different techniques can be used to generate these parameters [8].

\subsubsection{Porosity Model}

Porosity model was built depending on the results of porosity logs (density and neutron) which have been corrected and interpreted in the IP software .

As porosity modeling is concerned, no seismic attributes that may be used as a predictor have been identified. Therefore, the $3 \mathrm{D}$ distribution of the porosity is based on the vertical well profiles. The well data are transformed (normal score) so they are approximately Gaussian distributed. The Gaussian model is characterized by various statistical parameters, which reflect the spatial variability of the porosity[8].

The variogram parameters indicate to what degree the measured porosity values in a position can impact the unobserved porosity values in a position nearby. First, a sequential screening algorithm simulates one realization of an unconditional Gaussian field. The grid cells that correspond to well trajectories are each assigned to a value corresponding to the measured upscaled well logs. The cells with the values for the well trajectories are "merged" with the unconditional Gaussian field. This is done by standard kriging techniques and results in a conditional Gaussian field that honors the well logs, standard deviations, and variograms specified [8].

\subsubsection{Water Saturation Model}

Water Saturation is calculated based on distributions related to porosity ranges. The full range of porosity has been divided into five arbitrary classes in which associated Water Saturation values from logs were statistically analyzed. It turned out that within each porosity class, related Water Saturation data fit a log normal distribution. These distributions condition perfectly the modeling of the Water Saturation for each porosity class. This fast and simple method allows the generation of a consistent water saturation distribution that respects a realistic degree of correlation between porosity and saturation. With this simple technique, the distribution of the saturation is performed in one step for all the reservoir cells that are located above the Oil-Water Contact (OWC).

The definition of this hydrocarbon contact is complicated due to the small density contrast between the oil and the water, the occurrence of a flushed zone, the heterogeneous character of the reservoir, and poor well borehole conditions that negatively impact on the acquisition of reliable geological data. The definition of the OWC is therefore possible by a complete and simultaneous analysis of different types of data: conventional logs, resonance magnetic logs, wireline tester pretests, drill stem tests, and cores [8].

The same geostatistical method of porosity model was used in the water saturation model. After the scale up of water saturation that exported from IP software the water saturation model was built for each reservoir unit of the Mishrif Formation in the Amara Field.

\section{RESULTS AND DISCUSSIONS}

This study has constructed based on thirteen wells (Am-1 to Am-13) penetrated Mishrif formation in Amara Oil Field. Three Dimension modeling has built depending to 12 wells (Am-1 to Am-12)for Mishrif formation. All wells have PHIE and Water Saturation logs, which exported from interactive petrophysics (IP v3.6) software. Thereafter, scale up well logs has carried out for these wells.

To building the model, there are different methods of distribution of petrophysical properties. These methods involve (l. Gaussian Random Function Simulation 2. Sequential Gaussian Simulation 3. Kriging 4. Kriging interpolation 5. Kriging (Gslib) 6. Functional 7. Moving average 8. Closest). Eight methods have executed in order to propagate property values through construct Porosity and Water Saturation Models. Depending on results, the project has eight water saturation models and eight porosity models

Then insert new well (Am-13) to the models and create Porosity and Water Saturation logs from the Porosity and Water Saturation models where the new well penetrated the models in points that it have values of Porosity and Water Saturation. Therefore, the new well has Porosity and water saturation logs for each method. With variety methods of distribution of petrophysical properties, consequently, different inresults. 
Depending on comparing the results from Log interpretation and the results from modeling, Sequential Gaussian Simulation suitable algorithm method to build the 3D modeling for Mishrif formation in Amara Oil Field.

The results of the eight methods have shown in the following figures that have named in PHIE (U), SW (U) refers to the results from modeling and PHIE13 (U), and SW13 (U) refers to the results from log interpretation.
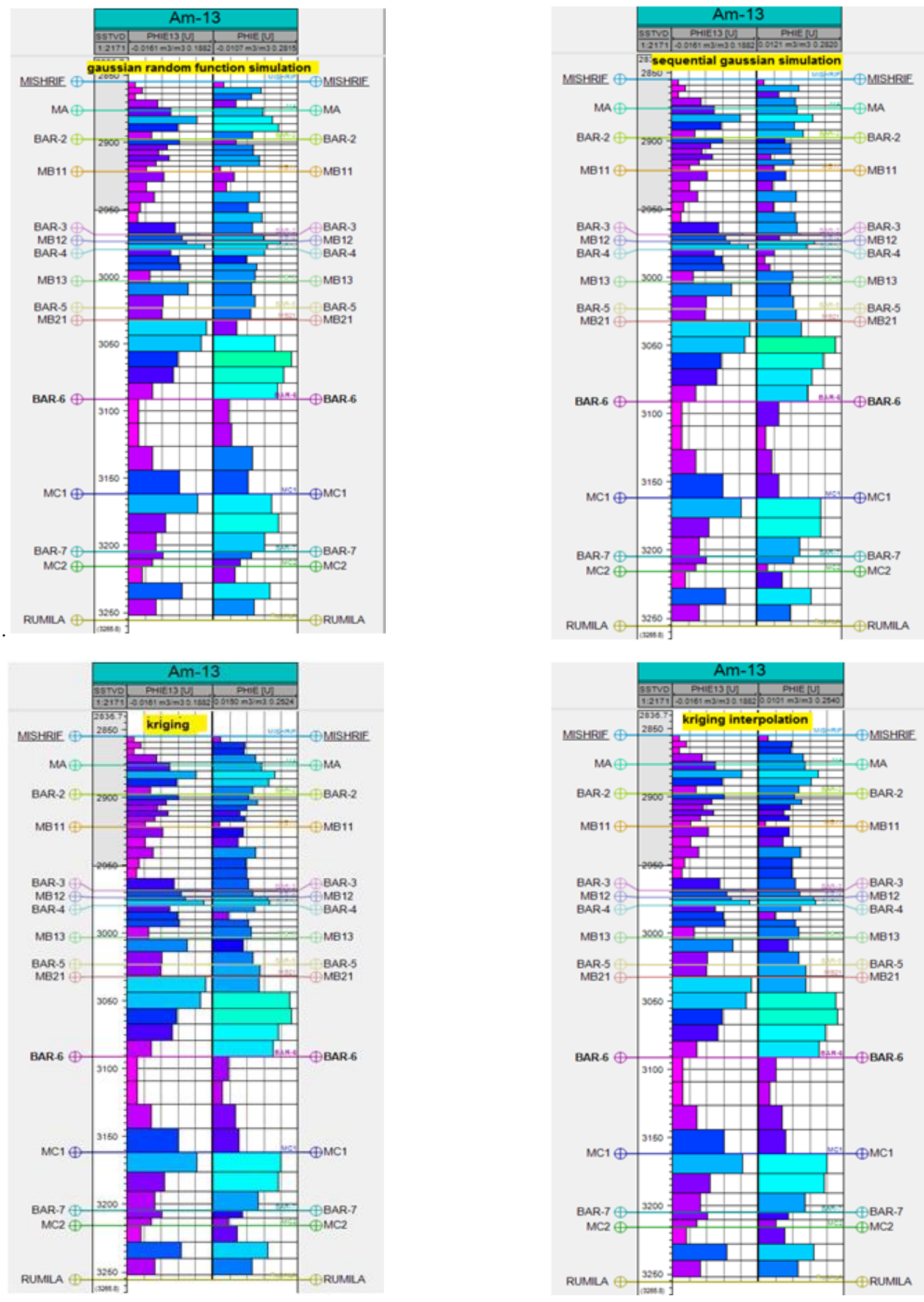

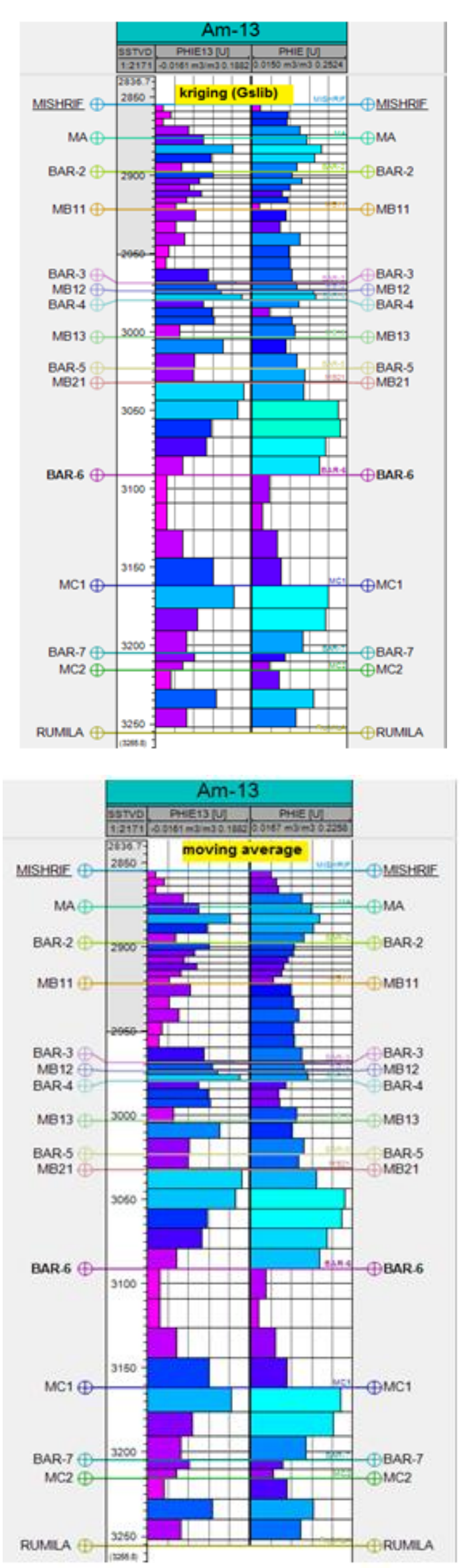
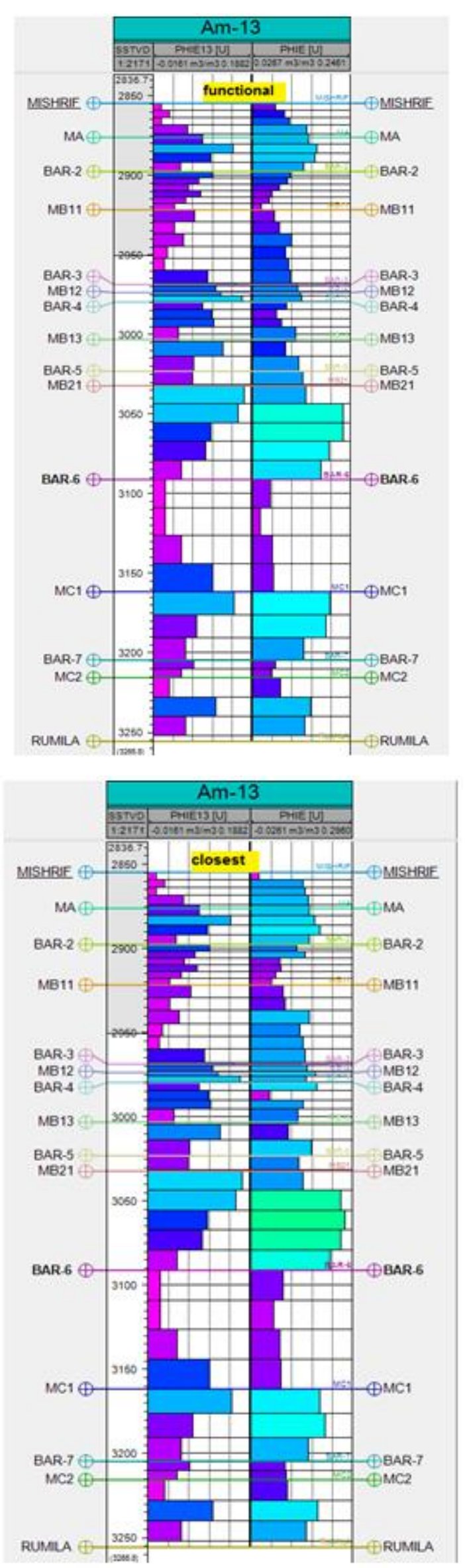

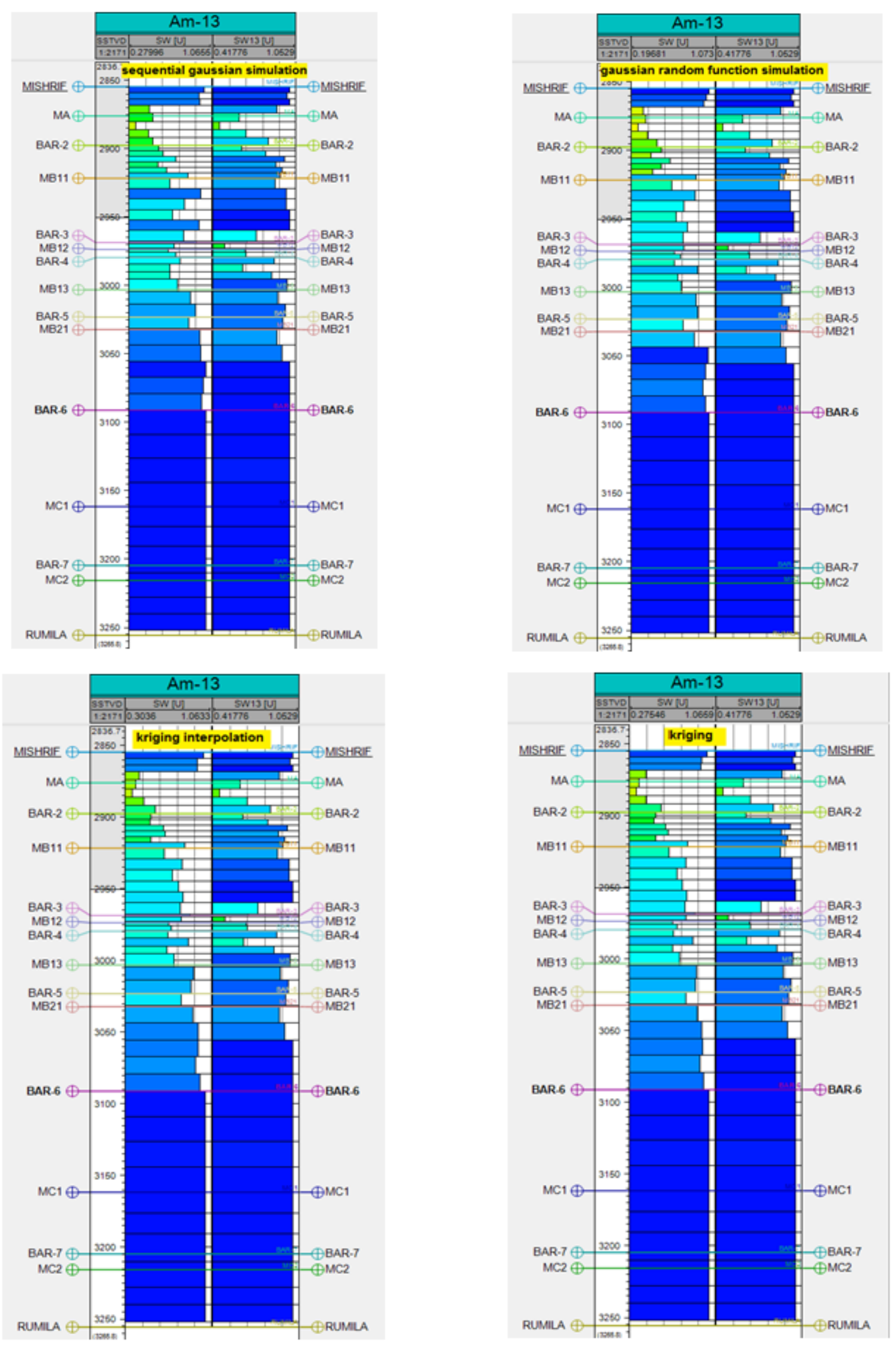

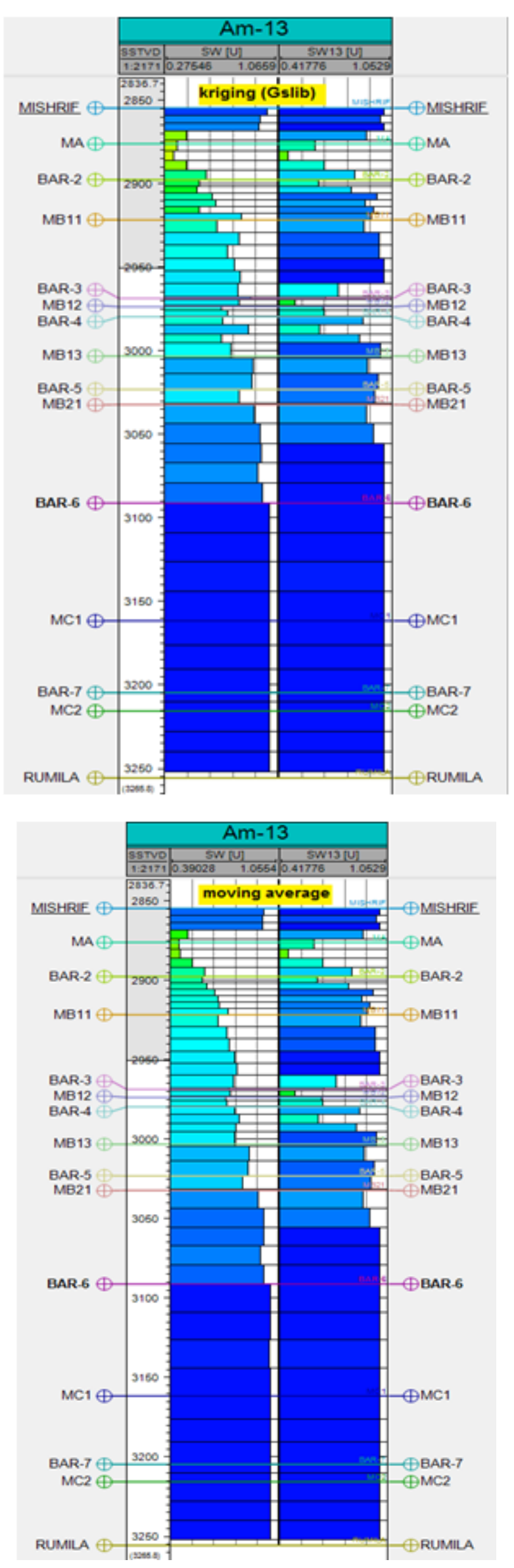
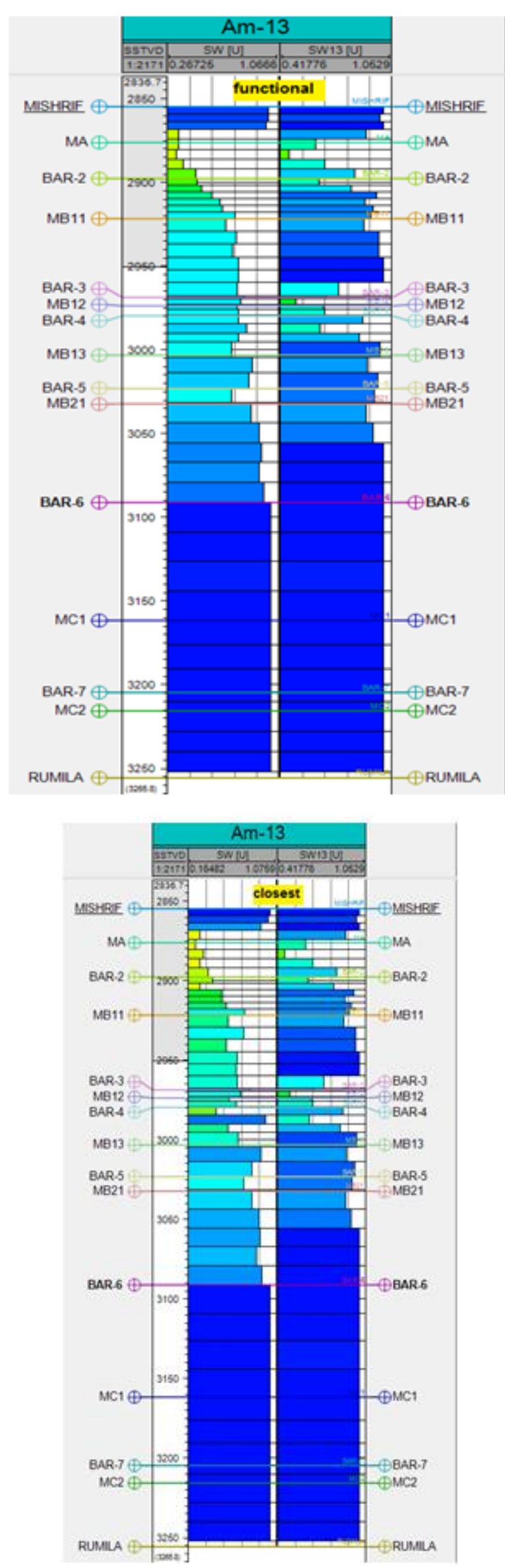


\section{CONCLUSION AND RECOMMENDATION}

Depending on the results, there are not data from the modeling corresponding exactly to the true data from the $\log$ interpretation for the same well, but it approximate from the true data in different percentage .The quality of the results strongly reliance on the type of the method. Sequential Gaussian Simulation suitable algorithm method to build the 3D modeling for Mishrif formation.

\section{REFERENCES}

[1] B. Doligez, H. Beucher, F. Geffroy, eta R. Eschard, «Integrated Reservoir Characterization: Improvement in Heterogeneity stochastic Modeling by integration of additional external constraints», AAPG, or. 333-342, 1999.

[2] Schlumberger, Petrel Seismic to Simulation Software, libk. 1. Schlumberger, 2010.

[3] O.-C. Adaeze eta A. U.P, «FACIES MODELLING AND PETROPHSICAL PROPERTIES OF X-FIELD, ONSHORE, NIGER DELTA, NIGERIA», Int. J. Sci. Invent. Today, libk. 5, zenb. 2, or. 136-151, 2016.

[4] G. Caumon, P. Collon-Drouaillet, C. Le Carlier De Veslud, S. Viseur, eta J. Sausse, «Surface-based 3D modeling of geological structures», Math. Geosci., libk. 41, zenb. 8, or. 927-945, 2009.

[5] J. Richard H. Groshong, 3-D Structural Geology A. 2006.

[6] Schlumberger, Petrel Introduction Course. 2007.

[7] Schlumberger, Reservoir Engineering Course Petrel 2010. Houston, 2010.

[8] B. Johnny et al., «Definition of a 3D integrated Geological Model in a Complex and Extensive Heavy Oil Field, Oficina Formation, Faja de Orinoco, Venezuela», AAPG Annu. Meet., zenb. Figure 2, 2003. 